\title{
PENGARUH CAMPURAN TANAH GAMBUT DAN PUPUK KANDANG AYAM TERHADAP PERTUMBUHAN Caliandra callothyrsus
}

(The Effect of Mixing Peat and Chicken Manure to Caliandra callothyrsus Growth)

\author{
Adizar razzaq ichsani, Burhanuddin, Siti latifah \\ Fakultas Kehutanan Universitas Tanjungpura, JL. Daya Nasional Pontianak, 78124 \\ e-mail: adizarrazzaq@gmail.com
}

\begin{abstract}
Kaliandra (Calliandra callothyrsus) is a plant that include of Fabaceae family. Kaliandra has 200 species in medium-sized tree with compounded flowers. benefits of Kaliandra can produce fast and qualified raw materials energy, especially for pellet production. Producing Energy is for commercial requirements about $4600 \mathrm{kcal}$ per $\mathrm{kg}$ of dry wood and $7200 \mathrm{kcal}$ per $\mathrm{kg}$ of charcoal. This research purpose to get the best media in Kaliandra growth. The method of research has been used by Completely Randomized Design (CRD). The research consisted by 6 treatments of planting medias (M0, M1, M2, M3, M4, M5). Those treatments have been 5th replicated therefore become 30 experimental units. This results showed best media is M5 (peat soil : Chicken Manure $=3: 1)$. M5 is best plant growth media.
\end{abstract}

Keywords : Calliandra growth at peat media

Abstrak

Kaliandra (Caliandra callothyrsus) merupakan tanaman anggota family Fabaceae. Kaliandra memiliki anggota sekitar 200 jenis wujudnya berupa pohon berukuran sedang dengan bunga tersusun majemuk. Manfaat dari Kaliandra dapat menghasilkan bahan baku energi secara cepat dan berkualitas terutama untuk produksi pelet. Energi dihasilkan untuk syarat komersial sekitar $4600 \mathrm{kkal}$ per $\mathrm{kg}$ kayu kering dan $7200 \mathrm{kkal}$ panas per $\mathrm{kg}$ arang. Penelitian ini bertujuan untuk mendapatkan media terbaik dalam pertumbuhan Kaliandra. Metode yang digunakan adalah eksperimen dirancang menggunakan Rancangan Acak Lengkap (RAL). Percobaan terdiri dari 6 perlakuan media tanam (M0, M1, M2, M3, M4, M5). Penelitian ini menggunakan 5 kali ulangan sehingga terdapat 30 unit percobaan. Hasil penelitian menunjukan bahwa media terbaik adalah M5(Tanah gambut: Pupuk kandang ayam = 3:1). Media M5 merupakan media dengan pertumbuhan tanaman terbaik.

Kata kunci: Pertumbuhan kaliandra pada media gambut

\section{PENDAHULUAN}

Kaliandra (Caliandra callothyrsus) merupakan tanaman anggota famili Fabaceae dengan anggota sekitar 200 jenis wujudnya berupa pohon berukuran sedang dengan bunga tersusun majemuk. Kaliandra banyak digunakan untuk pakan ternak, manfaat lain dari Kaliandra dapat menghasilkan bahan baku energi secara cepat. Kalimantan sebagian besar tanahnya adalah tanah gambut. Gambut merupakan tanah yang miskin unsur hara dengan $\mathrm{pH}$ rendah. Penanaman kaliandra di tanah gambut terdapat kendala yaitu gambut memiliki $\mathrm{pH}$ rendah, dan tingkat kesuburan rendah karena sedikitnya unsur hara tersedia. Menurut Setadi et al (2016), sifat kimia tanah gambut yaitu memiliki ph tanah 3,61, ph air gambut 3,14, sementara kandungan hara nya yaitu C 56,78\%, N 0,84\%, P 79,02 ppm, K 2,61 ppm, Ca 3,36 ppm, Mg 1.63 ppm, Na 0,17 ppm, Fe 1,17 ppm, Nilai Tukar Kation (KTK) yaitu $47,23 \mathrm{me} / 100 \mathrm{~g}$. Sementara sifat fisika nya antara lain memiliki warna hitan dengan bobot isi 0,23 g/cm3, kadar air 250,83\%, kadar serat $19,55 \%$. 
Pertumbuhan bibit kaliandra yang berkualitas di persemaian dipengaruhi oleh kesuburan tanah, dengan demikian perlu perlakuan tambahan agar terdapat unsur hara mencukupi untuk Kaliandra. Untuk mengatasi masalah ketersediaan hara pada media gambut dalam pembibitan kaliandra ditambahkan pupuk kandang ayam. Pupuk kandang ayam mengandung banyak unsur hara makro seperti Ca, Mg, S, N, P, dan K. Menurut Sari et al. (2016) pupuk kandang ayam mempunyai potensi yang baik, karena selain berperan dalam memperbaiki sifat fisik, kimia, dan biologi tanah pupuk kandang ayam juga mempunyai kandungan $\mathrm{N}$, P, dan $\mathrm{K}$ yang lebih tinggi bila dibandingkan pupuk kandang lainnya. Menurut Andayani dan Sudiro (2013), kandungan Pada pupuk kandang ayam unsur haranya N 3,21 \%, P2O5 3,21\%, K2O 1,57 \%, Ca 1,57 \%, Mg 1,44 \%, Mn 250 ppm dan Zn 315 ppm, pupuk kandang sapi N 2,33 \%, P2O5 0,61 \%, K2O 1,58 \%, Ca 1,04\%, Mg 0,33 \%, Mn 179 ppm dan Zn 70,5 ppm. Dan pupuk kandang kambing $\mathrm{N} 2,10 \%, \mathrm{P} 2 \mathrm{O} 50,66 \%, \mathrm{~K} 2 \mathrm{O} 1,97 \%, \mathrm{Ca}$ 1,64 \%, Mg 0,60\%, Mn 233 ppm dan Zn 90,8 ppm. Menurut Sadari (2013) pupuk kandang ayam dan tanah alivial dengan perbandingan 1:4 memiliki pengaruh sangat nyata terhadap pertumbuhan diameter terhadap pertumbuhan tinggi, diameter dan jumlah daun pada rotan sega di persemaian, sementara perbandingan 1:2 sudah memberikan pengaruh terhadap pertumbuhan tinggi batang, diameter dan jumlah daun.

Pupuk kandang pada umumnya diberikan sebagai campuran pada tanah mineral atau tanah mineral, gambut dan pupuk kandang ayam. Pemberian pupuk kandang ayam pada tanah gambut saja tanpa tambahan tanah mineral bisa juga dilakukakun, namun belum di ketahui komposisi pupuk kandang ayam dan tanah gambut yang paling optimal terhadap pertumbuhan kaliandra di persemaian. Berdasarkan masalah tersebut perlu dilakukan penelitian untuk mendapatkan pengaruh pupuk kandang ayam dan komposisi yang paling optimal pada tanah gambut. Hasil penelitian ini diharapkan dapat menjadi acuan dalam memproduksi bibit kaliandra pada media tanah gambut.

\section{METODE PENELITIAN}

Metode penelitian yang digunakan dalam penenelitian ini adalah metode eksperimen perlakuan pemupukan pada tanah gambut. Perlakuan pemupukan pupuk organik terdiri atas beberapa perbandingan volume antara lain:

$\mathrm{M}_{0}=$ Tanah gambut

$\mathrm{M}_{1}=$ Tanah gambut $:$ Pupuk kandang ayam $=1: 1$

$\mathrm{M}_{2}=$ Tanah gambut $:$ Pupuk kandang ayam $=1: 2$

$\mathrm{M}_{3}=$ Tanah gambut $:$ Pupuk kandang ayam $=1: 3$

$\mathrm{M}_{4}=$ Tanah gambut $:$ Pupuk kandang ayam $=2: 1$

$\mathrm{M}_{5}=$ Tanah gambut $:$ Pupuk kandang ayam $=3: 1$

Alat dan Bahan

Alat yang digunakan dalam penelitian yaitu, polybag, kemera, spayer, thermohygrometer, penggaris, kalper. Bahan penelitian yaitu, biji kaliandra, pupuk kandang ayam, tanah gambut dan air.

\section{Pelaksanaan penelitian}

Pengolahan data pada penelitian ini menggunakan rancangan acak lengkap (RAL) dengan perlakuan media terdiri dari 6 tingkat perlakuan masing-masing perlakuan sebanyak 5 kali ulangan sehingga jumlah seluruhnya ada 30 sampel. Variabel yang di amati yaitu pertambahan tinggi tanaman $(\mathrm{cm})$, penambahan jumlah daun (helai), nilai RPA, nilai IMB. Analisis 
data dilekukan dengan menggunakan uji beda nyata terkeci (BNT).

HASIL DAN PEMBAHASAN

1. Pertambahan Tinggi Tanaman
Berdasarkan hasil pengamatan tinggi bibit Caliandra callothyrsus diperoleh nilai analisa sidik ragam. Hasil analisis sidik ragam tinggi Kaliandra dapat dilihat pada Tabel 1:

Tabel 1: Hasil analisa sidik ragam pengaruh media terhadap pertambahan tinggi (cm) bibit Caliandra callothyrsus. (The results of the analysis of the media influence variance on the increase in height (cm) of Caliandra callothyrsus seedlings)

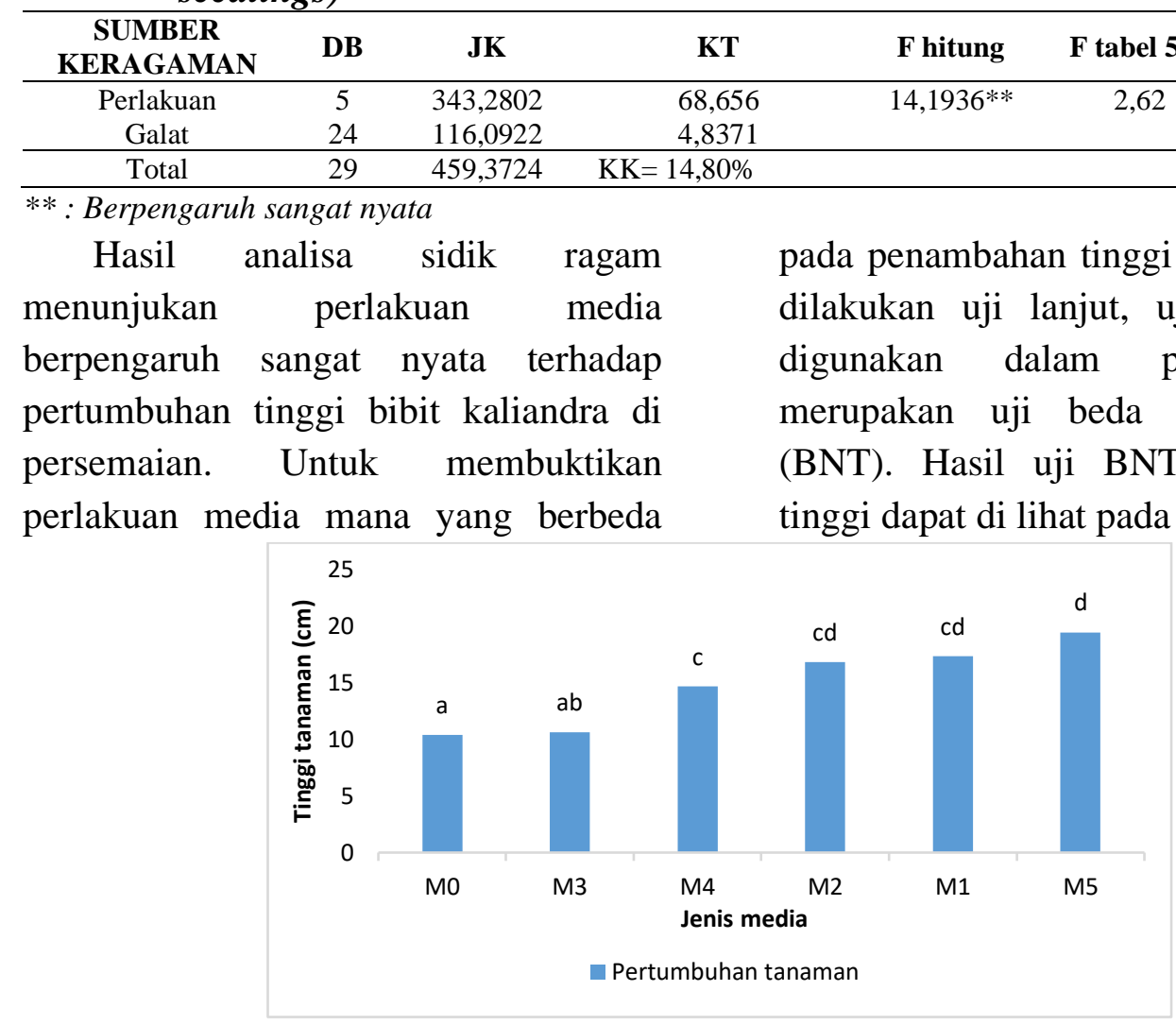

Keterangan:

Huruf yang sama pada histogram tidak berbeda nyata berdasarkan uji BNT taraf 5\%

$M_{3}=$ Tanah gambut $:$ Pupuk kandang ayam $=1: 3$

$M_{1}=$ Tanah gambut $:$ Pupuk kandang ayam = 1:1 $\quad M_{4}=$ Tanah gambut $:$ Pupuk kandang ayam = 2:1

$M_{2}=$ Tanah gambut $:$ Pupuk kandang ayam = 1:2 $M_{5}=$ Tanah gambut $:$ Pupuk kandang ayam = 3:1

Gambar 1:Grafik hasil uji BNT pertumbuhan tinggi $(\mathrm{cm})$ bibit kaliandra.

Berdasarkan (Gambar 1) terlihat bahwa jenis media M5 (campuran tanah gambut : pupuk kandang ayam 3:1) berbeda sangat nyata terhadap kontrol, M3, dan M4, terjadi penambahan tinggi sekitar $87 \%$ terhadap kontrol. Media M1 memberikan perbedaan nyata terhadap kontrol, dan M3, terjadi penambahan tinggi sekitar $64 \%$ terhadap kontrol. Media M2 berbeda sangat nyata terhadap kontrol dan M3, terjadi penambahan tingi tanaman sekitar $61 \%$ terhadap kontrol. Media yang tidak memberikan perbedaan nyata terhadap kontrol adalah media M3, dengan demikian media M5 merupakan media terbaik untuk 
pertumbuhan bibit Caliandra callothyrsus, namun media M5 tidak berbeda nyata terhadap M2 dan M1.

\section{Pertambahan Jumlah Daun.}

Berdasarkan hasil pengamatan jumlah daun bibit Caliandra

Tabel 2: Hasil analisa sidik ragam pengaruh media terhadap jumlah daun bibit Caliandra callothyrsus. (Result of analysis of variance of media influence on number of leaves of Caliandra callothyrsus seedling)

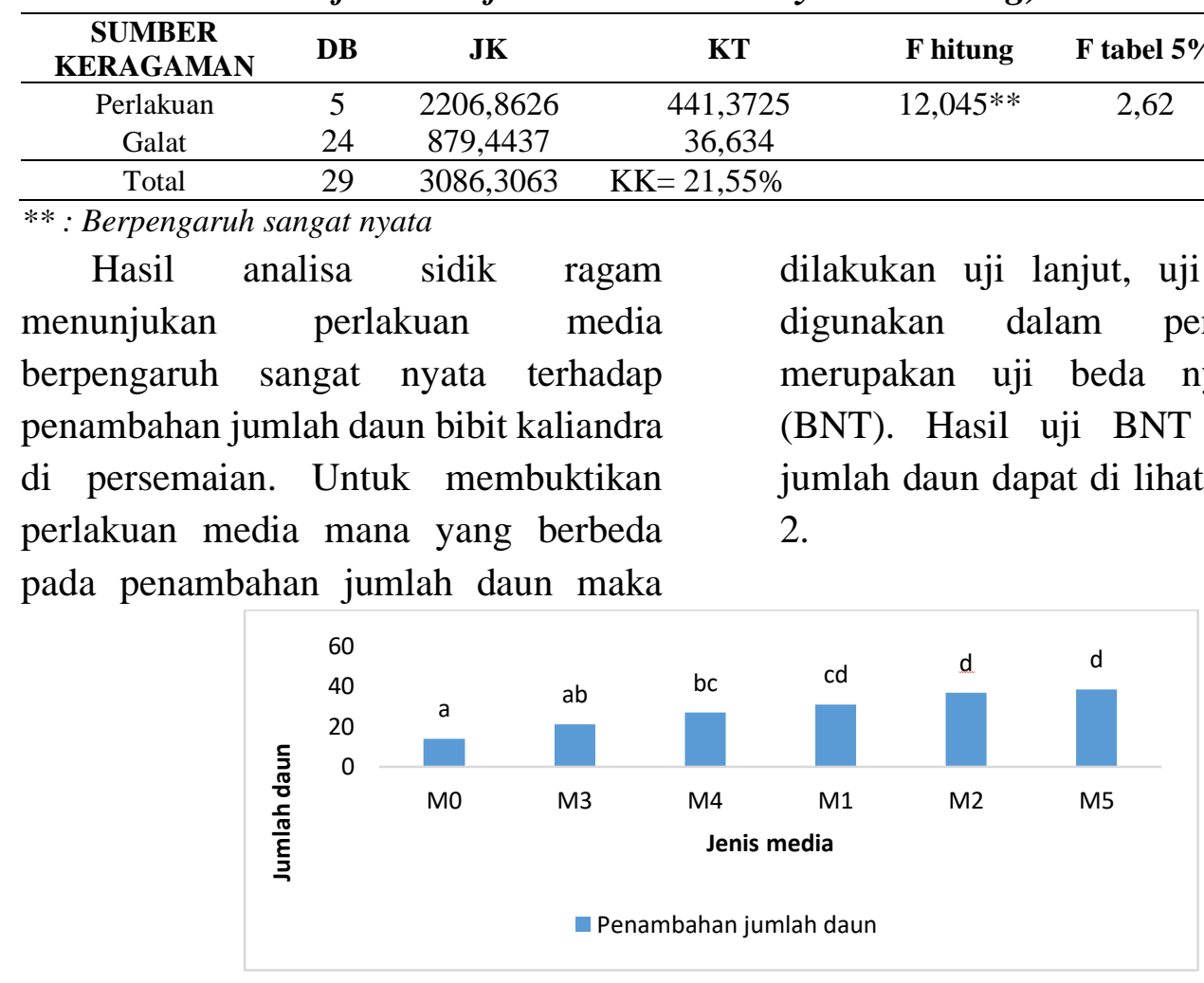

Keterangan:

Huruf yang sama pada histogram tidak berbeda nyata berdasarkan uji BNT taraf 5\%

$\mathrm{M}_{0}=$ Tanah gambut

$\mathbf{M}_{1}=$ Tanah gambut : Pupuk kandang ayam $=1: 1$

$\mathrm{M}_{2}=$ Tanah gambut : Pupuk kandang ayam = 1:2
$\mathrm{M}_{3}=$ Tanah gambut : Pupuk kandang ayam $=1: 3$

$\mathrm{M}_{4}=$ Tanah gambut $:$ Pupuk kandang ayam $=2: 1$

$\mathrm{M}_{5}=$ Tanah gambut $:$ Pupuk kandang ayam = 3:1

\section{Gambar 2: Grafik hasil uji BNT jumlah daun pada bibit kaliandra.}

Berdasarkan (Gambar 2) terlihat bahwa jenis media Media M5 (campuran tanah gambut : pupuk kandang ayam 3:1) berbeda sangat nyata terhadap kontrol, M4, dan M3, terjadi penambahan jumlah daun sekitar $172 \%$ terhadap kontrol. Media M2 memberikan perbedaan nyata terhadap kontrol, M3, dan M4, terjadi penambahan jumlah daun sekitar 162\% terhadap kontrol. Media M1 memiliki perbedaan sangat nyata terhadap kontrol, dan M3, terjadi penambahan jumlah daun sekitar $120 \%$ terhadap kontrol. Media M5 juga menunjukan pengaruh sangat nyata terhadap semua perlakuan yang di uji kecuali terhadap M2, dengan demikian media M5 merupakan media terbaik untuk penambahan jumlah daun Caliandra callothyrsus, media M5 tidak berbeda nyata terhadap M1 dan M2. 


\section{Nilai Rasio Pucuk Akar (RPA)}

Berdasarkan hasil pengamatan Rasio Pucuk Akar (RPA) bibit Caliandra callothyrsus diperoleh nilai

Tabel 3: Hasil analisa sidik ragam pengaruh media terhadap RPA Caliandra callothyrsus. (Result of analysis of variance of media influence on RPA Caliandra callothyrsus)

\begin{tabular}{|c|c|c|c|c|c|c|}
\hline $\begin{array}{c}\text { SUMBER } \\
\text { KERAGAMAN }\end{array}$ & DB & JK & KT & F hitung & F tabel 5\% & $F$ tabel 1\% \\
\hline Perlakuan & 5 & 13,7497 & 2,7499 & $3,4233^{*}$ & 2,62 & 3,9 \\
\hline Galat & 24 & 33,924 & 1,4135 & & & \\
\hline Total & 29 & 47,6731 & $\mathrm{KK}=34,72 \%$ & & & \\
\hline
\end{tabular}

*: Berpengaruh nyata

Hasil analisa sidik ragam menunjukan bahwa perlakuan media berpengaruh sangat nyata terhadap nilai RPA bibit kaliandra di persemaian. Untuk membuktikan perlakuan media mana yang berbeda pada nilai RPA

analisis sidik ragam. Hasil dari analisis sidik ragam nilai RPA dapat dilihat pada Tabel 3. kaliandra maka dilakukan uji lanjut, uji lanjut dalam penelitian ini merupakan uji beda nyata terkecil (BNT). Hasil uji BNT penambahan jumlah daun dapat di lihat pada Gambar 3:

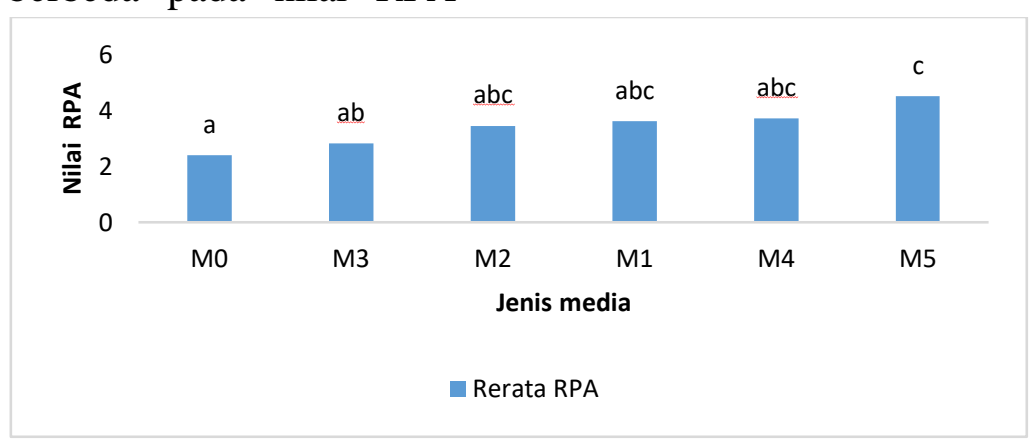

Keterangan:

Huruf yang sama pada histogram tidak berbeda nyata berdasarkan uji BNT taraf 5\%

$\mathrm{M}_{0}=$ Tanah gambut

$\mathrm{M}_{3}=$ Tanah gambut : Pupuk kandang ayam $=1: 3$

$\mathbf{M}_{1}=$ Tanah gambut $:$ Pupuk kandang ayam $=1: 1$

$\mathbf{M}_{4}=$ Tanah gambut $:$ Pupuk kandang ayam $=2: 1$

$\mathrm{M}_{2}=$ Tanah gambut $:$ Pupuk kandang ayam = 1:2

$\mathrm{M}_{5}=$ Tanah gambut $:$ Pupuk kandang ayam $=3: 1$

Gambar 3: Grafik hasil uji BNT rasio pucuk akar (RPA) pada bibit kaliandra.

Berdasarkan (Gambar 3) terlihat bahwa M5 (campuran tanah gambut : pupuk kandang ayam 3:1) berbeda sangat nyata terhadap kontrol dan berbeda nyata terhadap M3, terjadi penambahan nilai RPA sekitar $88 \%$ terhadap kontrol. Media M4 tidak memberikan perbedaan nyata terhadap perlakuan lainnya, terjadi penambahan nilai RPA sekitar 55\% terhadap kontrol. Media M1 tidak memberikan perbedaan nyata terhadap perlakuan lainnya, terjadi penambahan nilai RPA sekitar 50\% terhadap kontrol. Dengan demikian media M5 merupakan media yang terbaik untuk RPA, tetapi media M5 tidak berbeda nyata terhadap M2, M1, dan M4.

\section{Nilai Indeks Mutu Bibit (IMB)}

Berdasarkan hasil pengamatan Indeks Mutu Bibit (IMB) bibit Caliandra callothyrsus diperoleh nilai analisis sidik ragam. Hasil analisis sidik 
ragam nilai IMB dapat di lihat pada

Tabel 4.

Tabel 4: Hasil analisa sidik ragam pengaruh media terhadap IMB Caliandra callothyrsus.

\begin{tabular}{ccccccc}
\hline $\begin{array}{c}\text { SUMBER } \\
\text { KERAGAMAN }\end{array}$ & DB & JK & KT & F hitung & F tabel 5\% & F tabel 1\% \\
\hline Perlakuan & 5 & 0,7571 & 0,1514 & $4,9477 * *$ & 2,62 & 3,9 \\
Galat & 24 & 0,7346 & 0,0306 & & & \\
\hline Total & 29 & 1,4917 & $\mathrm{KK}=59,69 \%$ & & \\
**: Berpengaruh sangat nyata & \multicolumn{7}{l}{}
\end{tabular}

Hasil analisa sidik ragam kaliandra maka dilakukan uji lanjut, uji menunjukan bahwa perlakuan media lanjut yang digunakan dalam penelitian berpengaruh sangat nyata terhadap nilai ini merupakan uji beda nyata terkecil IMB bibit kaliandra di persemaian. (BNT). Hasil uji BNT penambahan Untuk membuktikan perlakuan media jumlah daun dapat di lihat pada Gambar mana yang berbeda pada nilai IMB bibit $\quad 4$ :

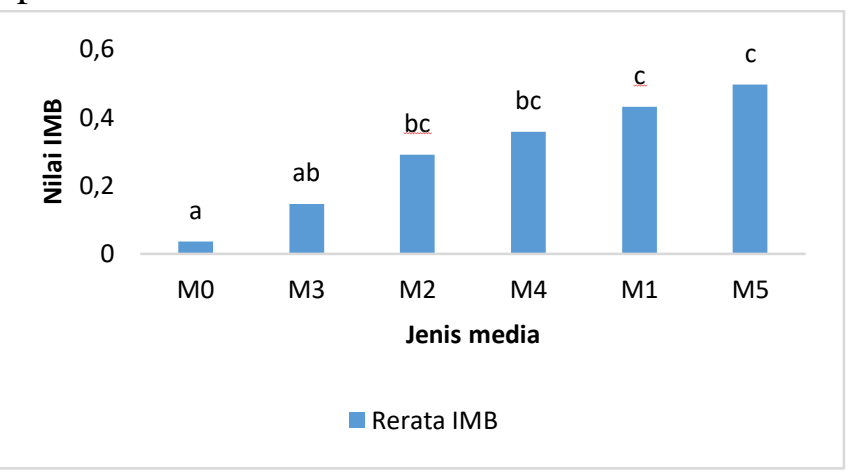

Keterangan:

Huruf yang sama pada histogram tidak berbeda nyata berdasarkan uji BNT taraf 5\%

$\mathrm{M}_{0}=$ Tanah gambut

$\mathrm{M}_{3}=$ Tanah gambut $:$ Pupuk kandang ayam $=1: 3$

$\mathrm{M}_{1}=$ Tanah gambut $:$ Pupuk kandang ayam $=1: 1$

$\mathrm{M}_{4}=$ Tanah gambut $:$ Pupuk kandang ayam $=2: 1$

$\mathbf{M}_{2}=$ Tanah gambut : Pupuk kandang ayam = 1:2

$\mathrm{M}_{5}=$ Tanah gambut $:$ Pupuk kandang ayam = 3:1

Gambar 4: Grafik hasil uji BNT Indeks Mutu Bibit (IMB) pada bibit kaliandra.

Berdasarkan (Gambar 4) terlihat bahwa M5 (campuran tanah gambut : pupuk kandang ayam 3:1) berbeda sangat nyata terhadap kontrol dan M3 terjadi penambahan nilai IMB sekitar $1233 \%$ terhadap kontrol. Media M4 memberikan perbedaan sangat nyata terhadap kontrol, terjadi penambahan nilai IMB sekitar $877 \%$ terhadap kontrol. Media M1 berbeda sangat nyata terhadap kontrol, dan berbeda nyata terhadap M3, terjadi penambahan nilai IMB sekitar 1069\% terhadap kontrol. Dengan demikian media M5 merupakan media yang terbaik untuk IMB, tetapi media
M5 tidak menunjukan perbedaan nyata terhadap M2, M4, dan M1.

Pada bagian koefisien keragaman (KK) Tabel 1 memiliki nilai KK 14,80\%, Tabel 2 sebesar $21,55 \%$, Tabel 3 sebesar 34,72\%, dan Tabel 4 sebesar 59,69\%. Nilai KK tersebut terlalu besar bagi penelitian yang homogen. Menurut Kemas (2016) KK yang baik untuk percobaan-percobaan di rumah kaca atau laboratorium atau di ruang-ruang terkontrol lainnya adalah antara 5-10\% dan untuk percobaan di lapangan adalah 10-20\%. Hal ini disebabkan oleh 
perbedaan total volume setiap perlakuan berbeda.

\section{Pengaruh lingkungan (suhu dan kelembaban)}

Faktor lingkungan suhu dan kelembaban udara dapat mempengaruhi pertumbuhan tanaman. Pengamatan suhu menggunakan alat termohigrometer digital yang ditempatkan pada lokasi penelitian, waktu yang dilakukan untuk pengamatan suhu dan kelembaban yaitu pagi pukul 06.00 WIB, siang hari pukul 12.00 WIB, dan sore hari pukul 17.30 WIB. Selama pengamatan rata-rata suhu yaitu $24^{\circ} \mathrm{C}$ pada pagi hari, pada siang hari suhu rata-rata yaitu sebesar $32^{\circ} \mathrm{C}$, pada sore hari suhu yang diamati memiliki rata-rata $26^{\circ} \mathrm{C}$. Untuk kelembaban hasil pengamatan yang didapatkan yaitu 99\% pada pagi hari, $61 \%$ pada siang hari dan $79 \%$ pada waktu sore hari. Pertumbuhan tanaman sangat dipengauhi oleh suhu dan kelembaban lingkungan kaliandra tumbuh di daerah dengan suhu minimum tahunan $18-22^{0} \mathrm{C}$ dan tidak tahan terhadap pembekuan. Seperti pendapat Santoso dan Nursandi (2003) menyatakan secara umum temperatur yang dibutuhkan tanaman untuk dapat dapat tumbuh dengan baik berkisar $20^{\circ} \mathrm{C}-30^{\circ} \mathrm{C}$. Dengan demilkian rata-rata suhu dan kelembaban selama penelitian di persemaian telah memenuhi syarat pertumbuhan kaliandra

\section{KESIMPULAN}

Berdasarkan hasil penelitian dapat diambil kesimpulan bahwa perlakuan terbaik terhadap pertumbuhan kaliandra (Caliandra callothyrsus) yaitu perlakuan tanah gambut : Pupuk kandang ayam = 3:1 (M5). Media M5 merupakan media terbaik karena memiliki nilai rerata tertiggi dengan nilai rerata 19,43 untuk tinggi tanaman, 38,482 untuk jumlah daun, 4,52 untuk nilai Rasio Pucuk Akar (RPA), dan 0,49561 untuk nilai Indeks Mutu Bibit. Hasil analisa sidik ragam juga menunjukan pengaruh nyata terhadap semua parameter pertumbuhan tanaman kaliandra (Caliandra callothyrsus) terhadap kontrol.

\section{DAFTAR PUSTAKA}

Andayani dan Sarido L. 2013. Uji Empat Jenis Pupuk Kandang Terhadap Pertumbuhan Dan Hasil Tanaman Cabai Keriting (Capsicum annum L.). Jurnal AGRIFOR Volume XII 1: 22-29

Baherta. 2009. Respon Bibit Kopi Arabika Pada Beberapa Takaran Pupuk Kandang Kotoran Ayam. Jurnal Ilmiah Tambua, 8 (1) :467472.

Fajri M \& Ngatiman. 2017. Studi Iklim Mikro dan Topografi Pada Habitat Parashorea Malaanonan Merr Study of Microclimate and Topography at Parashorea malaanonan Merr Habita Jurnal Penelitian Ekosistem Dipterokarpa 1: $1-12$

Fajri M dan Ngatiman. 2017. Studi Iklim Mikro Dan Topografi Pada Habitat Parashorea Malaanonan Merr. Jurnal Penelitian Ekosistem Dipterokarpa 1: 1-12

Fitra SJ, Prijono S, Maswar. 2019. Pengaruh Pemupukan Pada Lahan Gambut Terhadap Karakteristik Tanah, Emisi CO2, Dan Produktivitas Tanaman Karet. Jurnal Tanah dan Sumberdaya Lahan $1: 1145-1156$

Hariyadi. 2018. Respon Pertumbuhan Tanaman Jagung Manis (Zea Mays 
L. Saccharata Sturt) Terhadap Pemberian Kotoran Ayam Dan Guano Walet Pada Tanah Gambut Pedalaman. Jurnal Matematika, Sains, dan Teknolog 2: 72-79

Hayati, Et. Mahmud, Fazil R. 2012. Pengaruh Jenis Pupuk Organik Dan Varietas Terhadap Pertumbuhan Dan Hasil Tanaman Cabai (Capsicum Annum L.). J. Floratek 7: 173 - 181

Hendrati R L, Suwandi, Margiyanti. 2014. Budidaya Kaliandra (Calliandra calothyrsus) Untuk Bahan Baku Sumber Energi. IPB press: Bogor

Karmila R dan Andriani V. 2019. Pengaruh Temperatur Terhadap Kecepatan Pertumbuhan Kacang Tolo (Vigna sp.) . jurnal UNIPA 1:49-53

Kemas AL. 2016. Rancangan

Percobaan: Teori dan Aplikasi.

Rajawali Pers: Jakarta

Mannetje L. dan Jones. R.M. 1992. Prosea, Plant Resources of SouthEast Asia 4, Forages. Bogor: Pudoc Scientific Publisher.

Maryani dan Tatik A. 2012. Pengaruh Volume Pemberian Air Terhadap Pertumbuhan Bibit Kelapa Sawit
Di Pembibitan Utama. Jurnal Fakultas pertanian 2: 52-65.

Nio S A dan Yunia B. 2011.

Konsentrasi Klorofil Daun

Sebagai Indikator Kekurangan Air Pada Tanaman. Jurnal Ilmiah Sains 2: 167-173

Radjagukguk, B. 1997. Peat soil of Indonesia: Location, classification, and problems for sustainability. In: Rieley and Page (Eds.). pp. 45-54. Biodiversity and sustainability of tropical peat and peatland. Samara Publishing Ltd. Cardigan. UK.

Santoso U. Nursandi F. 2003. Kultur Jaringan Tanaman. Malang: Universitas Muhmmadiyah Malang Press.

Sari KM, Pasigai A, Wahyudi I. 2016. Pengaruh Pupuk Kandang Ayam Terhadap Pertumbuhan Dan Hasil Tanaman Kubis Bunga (Brassica oleracea Var. Bathytis L.) Pada Oxic Dystrudepts Lembantongoa e-J. Agrotekbis $2: 151-159$.

Setiadi, I. C. Yulianti, N. Adji, F.F. 2016. Evaluasi Sifat Kimia Dan Fisik Gambut Dari Beberapa Lokasi di Blok C EKS-PLG Kalimantan Tengah. Jurnal AGRI PEAT 2:6778 